\title{
GIS 在水文水资源领域的应用探究
}

\author{
习贵芳 ${ }^{1}$ 严小龙 ${ }^{2}$ \\ 1 广东省水利电力勘测设计研究院重庆分院 2 长江勘测规划设计研究有限责任公司 \\ DOI:10.32629/hwr.v3i11.2480
}

[ 摘 要] 如今,水文水源勘测工作受到了人们的高度关注。GIS技术在水源勘测工作中,获取信息更加顺畅,可实现信息资料的可视化,提高水文 水资源勘测水平。本文就将分析GIS在水文水资源领域的应用,以供借鉴。

[关键词] GIS; 水文水资源；信息可视化

水资源是人们社会生产和生活的基础性资源, 但我国水资源现状不容 乐观, 水资源污染和短缺现象严重。所以水资源管理成为相关部门的首要 任务。而GIS技术优势明显, 其可在水文水资源领域发挥最大作用。

\section{1 地理信息系统}

GIS即地理信息系统, 是一种应用广泛的空间信息系统, 该系统以计算 机软硬件系统为基础采集、存储、管理、运算、分析和显示空间中的地理 数据, 同时还可实现信息数据分析描述, 是一个综合性的技术系统。

\section{GIS 在水文水资源领域的应用}

2.1 水资源开发与管理中GIS的应用分析

2.1. 1 水资源开发

在应用GIS技术后, 地表水资源调查的效率显著提高, 调查结果也更为 准确。除地表水调查, GIS技术还可应用于地下水调查, 其可应用更加科学 合理的方式分析地下水开采的基本情况, 加强地下水资源保护。而水资源 开发的合理性显著增强, 有利于水资源开发的科学决策。

\section{1 .2 水资源管理}

现阶段, 我国建立了多种不同形式的GIS水资源管理系统, GIS技术在 我国水资源管理中的应用具有较为明显的规模效应。如黄河下游水资源管 理空间决策支持系统等, 均为以GIS技术为基础建立的技术系统, 提高了我 国水资源开发的合理性, 促进了我国水资源的可持续利用。当前, 我国GIS 水资源管理信息系统技术水平与发达国家基本相同, 且在发展中也形成了 显著的自身特色。

首先, 我国基础电子地图系统数据中, 基础数据的参数为 $1: 25$ 万, 其中 重事故频发区的勘察工作, 针对危险系数大的工作, 要对工作人员进行全 面保护。同时, 安全管理人员需要在施工现场危险位置设置标语, 各个工作 人员需要佩戴相应的安全防护设施进入施工现场, 还要加强对施工现场材 料、交通和人员的管理, 避免因机械设备和材料出现安全问题, 还要加强对 施工现场工作人员的培训, 召开安全宣传大会, 将安全工作落实到各个人 员身上, 定期针对施工人员开展培训活动, 向其讲解施工流程和施工技术, 这样施工人员能够严格按照标准和流程操作, 避免因操作失误引发安全问 题, 为水利工程质量和施工人员的人身安全提供保障。

\section{3优化目标责任书}

为了实现水利施工项目管理的预期效果, 相关管理人员需要引进有效 的项目管理办法。项目经理部和施工企业需要签订目标责任书, 明确双方 的合法权益、责任和义务, 实行契约式管理模式, 激发施工人员的工作积极 性, 不断实现个人利益和集体利益统一的目标。目标责任书是施工企业根 据经营管理和施工合同目标, 针对项目经理部的安全、进度、质量和成本 控制目标进行规定的文件, 是企业考核经理部门工作业绩的依据, 为项目 经理工作提供了指导 ${ }^{[3]}$ 。相关部门在设置目标责任书中各项目标时, 需要

涵盖的内容较多, 如行政区边界、城镇、铁路、公路、水库、居民点等多 种信息。

其次是专业的电子地图。专业电子地图主要指在电子地图上叠加数字 水文数字源专业地理数据所构成的电子地图, 专业电子地图的水文水资源 信息描述更加全面、具体, 且实用性更强, 其所蕴含的信息专业性也更强。

再次是遥感信息库。遥感信息库主要指的是与基础地理数据对应的遥 感遥测数据, 而遥感遥测数据只有通过专业手段破解方可获得。另外, 属性 数据库也是十分重要的组成部分。属性数据库能够准确地描述分区查询对 象的基本属性, 如区域内的水资源开发和利用现状、地表以及地下水资源 概况, 并且其也是GIS系统运行中十分重要的基础数据。

最后是软件系统。软件系统是以上述技术为基础, 利用GIS嵌入技术, 以水资源管理实际要求为目标, 开发和构建的水资源管理系统软件, 由 属性数据管理、空间数据管理以及空间与属性数据管理相结合的信息管 理组成。

2.2 GIS在水文情报预报中以及地下水资源勘察中的应用

2.2. 1水文情报的预报

首先要确定模型参数。流域水文模型中的各项参数与地理信息相关, 如流域的坡度、河流的长度宽度等。应用GIS技术能够结合地理信息数据 确定模型参数, 保证模型参数的准确性与可靠性, 且该技术还可根据地理 信息准确计算和分析流域下渗能力等参数。

其次是信息查询和空间信息分析。电子地图是预报系统运行的重要背 景, 利用GIS技术和数据管理技术能够查询、检索、分析和计算水情信息。

充分考虑企业管理和项目施工要求, 合理地设置施工现场安全、进度、质 量、成本和标准化管理等内容。

\section{5 结束语}

综上所述, 水利施工项目管理是不断变化的, 在项目管理工作实施过 程中极易受到各种要素的相互作用和相互影响。在水利工程项目建设中, 为了更好地开展水利施工企业项目管理工作, 相关管理部门需要深入分析 水利施工企业项目管理特点, 建立企业项目管理的良性运行机制, 加强对 施工现场进度、安全等管理, 提高水利工程项目建设的整体质量, 为水利工 程项目建设的顺利实施提供支持。

\section{[参考文献]}

[1]高淑霞.探究水利施工技术发展现状和改革发展措施[J].工程建设 与设计,2019(12):213-214.

[2]郭芳,李茂.刍议水利施工企业项目管理关键问题[J].绿色环保建 材,2017(04):204.

[3]何沅晋, 朱姗, 廖文静.浅谈水利水电施工企业如何进行有效的项目 管理[J].四川水利,2018(1):82-84. 
DEM的应用对信息查询和空间信息分析具有十分重要的作用, 该技术可应 用于流域汇流计算和水利学模型构建。再者, 利用DEM技术还可准确高效地 分析和评估灾情。

最后是开发分布式水文模型。GIS系统的应用能够制定更加详细且准 确的信息资料, 工作人员可参照流域的基本条件将流域分成多个与基本条 件和要求相符的多边形或不规则的单元格, 在利用单元格的过程中, 要考 虑降雨量空间分布不均的特征, 以改进分布式水文模型开发质量。

\section{2.2 地下水资源的勘查}

在水资源保护、规划、管理和利用中, 地下水资源勘察发挥着关键作 用。地下水资源勘察主要的任务是明确区域内含水层的地层结构、空间分 布和含水层间水力的联系等重要参数。在地表水资源空间分布和调配过程 中, 应用GIS技术可更加准确地掌握地表水补给、地下水埋深和蕴藏量等重 要信息, 从而准确地构建数据成果的细化模型, 同时也可更加全面地体现 区域内地下水资源的规律和基本特点, 加强地下水资源保护、管理和开发 的合理性。

再者, 在水资源勘察工作中, 应用GIS能够建立科学完善的空间数据库 系统, 如地下水动态资料、水文地质基础资料和地下水开采概况等重要数 据, 不仅能够在可视条件下完成检索和查询, 还也可合理预测地下水动态 发展趋势, 发挥地下水资源管理空间辅助决策支持作用。

2.3 突发性水污染事故应急响应

在日常工作中, 若工作人员能够采取有效措施, 实现GIS技术空间数据 集成和网络分析功能、水质模拟技术的有机结合, 则可准确地模拟突发性 污染事故发生后, 水资源的污染概况, 进而以较快的速度明确影响对象和 范围, 然后采取更为有效的措施加大控制力度。如在严重的污染事故中, 可利用GIS技术建立预警系统及污染监测系统, 实现污水流动概况的动态 监测和控制, 评估其对沿线城市所造成的影响, 并分析其对污染变化的趋 势予以合理分析, 借助电子地图展示污染情况。电子地图能够更加生动直 观地展现水污染情况, 且其预测的准确性强, 可结合实际预警, 严格控制水 体污染。

\section{3 水文水资源中 GIS 技术应用的发展趋势}

我国水文水资源工作中, GIS技术应用越来越普遍, 但在发展中依然存 在着较为明显的不足, 需要相关人员对其展开系统研究。以下笔者就将分 析水文水资源中GIS技术应用的发展趋势。

3.1 GIS应用规范研究更为深入

GIS系统应用中, 工作人员应结合不同机构的生产实际采取不同的措 施。我国的标准开发和技术标准与发达国家相比, 存在着一定的不足, 其中 信息共享方面的问题尤为明显。虽然我国已经组织开展了试点工作, 但是 在工作中依然存在着很多需要不断改进和完善的部分, 因此在GIS应用的 过程中还需对技术应用规范予以全面深入地研究。

3.2 水文水资源空间决策系统更为完善
现阶段, GIS技术与决策支持系统的融合已经成为GIS技术的重要发展 趋势, 决策支持系统发展优势十分明显, 而且具有良好的发展前景, 这为后 续的运行奠定了坚实的基础。但是系统在应用和运行的过程中, 依然存在 较为明显的缺点。其中主要的问题在于开发难度较大, 系统开发需要投入 大量的资源和资金。这使得该技术无法得到推广和应用。我国虽然十分关 注系统应用试点工作的顺利开展, 加大力度推广, 但是由于系统自身的特 征, 依然面临重重困难。在我国现阶段的地质水文概况中, 长江和黄河在自 然条件和人文条件均具备建立资源空间决策体系的基础。

3. 3创建水文水资源空间决策支持系统

空间决策支持系统是现阶段较为先进的信息系统, 该系统以传统的决 策系统为基础, 与GIS技术的发展充分结合, 进而形成更为完善的综合性空 间决策支持系统。该系统在开发中面临着诸多的困境, 也需要消耗大量的 资金, 需要较多的人力支持, 因此受到了人们的大力关注。目前, 该技术依 然处于十分重要的发展时期, 待该系统技术成熟后, 方可对其进行大规模 和大范围推广应用。我国现阶段的发展中, 建立黄河水资源系统调度以及 黄河与常见的防洪决策支持系统成为了最为重要的任务, 只有积极建立完 善的系统, 才能推动区域水系的协调发展。

3.4 GIS与水文水资源专业模型深度融合

如今, 常用的水文资源模型多半融合了GIS技术, GIS技术在信息存储 和输送上具有十分显著的优势, 而数据是系统运行的核心。但是系统运行 中也存在着较为明显的不足, 其中空间分析和决策支持问题尤为显著, 该 问题在以RS和GIS技术为基础的分布式水文模型中十分普遍。故而在系统 建设和技术发展的过程中, 要采取有效措施将现有的多种计算方式和软件 顺利地转变为计算空间单元的分布式模型, 合理利用GIS技术的空间数据 管理功能, 实现水文水资源专业模型与GIS技术的高度融合, 这也成为了水 文水资源领域中十分重要的工作内容。

\section{4 结束语}

当前, 我国水利行业发展进程持续加快, 水利工程建设的数量日益增 多, 规模不断扩大, 在建设的过程中需要充分结合我国当前的发展概况, 以 经济发展为主要目的做好各项工作。在水利工程建设中, 水文水资源勘察 工作占据着重要的位置, 且GIS技术在水文水资源中也得到了广泛的应用。 该技术的应用一方面提高了水文水资源工作的质量, 另一方面也推动了我 国水利工程事业的快速发展, 因而值得大力推广与研究。

[参考文献]

[1]陈焕宝,施征,池云飞.GIS在水文水资源领域中的应用研究[J].珠江 水运,2018(15):69-70.

[2]间明丽.GIS技术在水文水资源领域的应用研究[J].科技风,2018(36):236.

[3]蒋公社,孙婕,李振.GIS技术在水文水资源领域的运用 [J].科技视 界,2019(01):259-260. 